\title{
Performance Pay, Group Selection and Group Performance
}

\author{
Manfred Königstein and Gabriele K. Ruchala*
}

March 2007

\begin{abstract}
Within a laboratory experiment we investigate a principal-agent game in which agents may, first, self-select into a group task (GT) or an individual task (IT) and, second, choose work effort. In their choices of task and effort the agents have to consider pay contracts for both tasks as offered by the principal. The rational solution of the game implies that contract design may not induce agents to select GT and provide positive effort in GT. Furthermore it predicts equal behavior of agents with different productivities. In contrast, considerations of trust, reciprocity and cooperation - the social-emotional model of behavior - suggest that contract design can influence the agents' willingness to join groups and provide effort. We analyze the data by applying a two-step regression model (multinomial logit and tobit) and find that counter to the rational solution, contract design does influence both, task selection and effort choice. The principal can increase participation in work groups and can positively influence group performance. Larger payment increases the share of socially motivated agents in work groups. The selection effect is larger than the motivation effect.
\end{abstract}

Keywords: principal-agent, experiment, work group, selection, motivation

JEL-Codes: M5, J3, C7, C9

Königstein: Dept. of Economics, University of Erfurt, manfred.koenigstein@uni-erfurt.de; Ruchala: Dept. of Economics and ELSE, University College London, g.ruchala@ucl.ac.uk. Königstein and Ruchala acknowledge financial support from the University of Erfurt. Ruchala is also grateful for additional funding from the Economic and Social Research Council (UK) via ELSE. 


\section{Introduction}

Among the most basic decisions to be taken by managers in organizations is the decision whether to organize work in groups (group tasks) or individually (individual tasks). Furthermore, given a certain task structure a decision has to be made upon the pay structure and the assignment of workers to tasks (job assignment). ${ }^{1}$ All three activities can strongly influence the productive effort of workers and, thus, the success of the organization. ${ }^{2}$ Forming work groups may increase individual productivity, e.g., since workers may benefit from an exchange of heterogeneous abilities or heterogeneous information. But group production may also induce monitoring problems causing shirking or other forms of organizational slackness (see, e.g., Prendergast (1999) for an overview). Furthermore, worker performance is influenced by monetary incentives. This is the core of principal-agent theory and it is highlighted, e.g., in an empirical study by LAZEAR (2000). LAZEAR identifies two separate effects of monetary incentives, a "motivation effect" and a "selection effect". The motivation effect captures increased effort of a firm's current work force, while the selection effect refers to changes in the composition of the work force. Both effects might occur also when workers may choose between an individual task and a group task.

We investigate these issues in a laboratory experiment. Relying on principal-agent theory we determine the basic relations between the pay structure designed by management (principal), the workers' (agents') choices of group task (GT) versus individual task (IT) and their productive efforts given a chosen task. We compare these theoretical predictions with observable behavior.

1 The adoption of teams in a natural environment (a garment plant) and the endogenous choice of (heterogeneous) workers to work either in a team or individually have recently been studied by HAMILTON, NICKERSON, and OWAN (2003). They find that the adoption of teams improved worker productivity; that productivity improvements were greatest for teams that formed earliest; and that high-ability workers tended to join teams first. Workers joining teams shifted from individual piece rates to group piece rate pay. Other case studies investigating the impact of group incentives are HANSEN (1997) and WEISS (1987).

2 The organization of labor is one key element for the success of each firm and the implementation of work teams has proven to be beneficial for companies (CHE and Yoo (2001), JEHN, NoRTHCRAFT, and NEALE (1999)). To date several experimental studies have examined how different explicit incentives affect workers' behavior. In particular, NALBANTIAN and SCHOTTER (1997) investigate the performance of various group incentive schemes, finding that competitive schemes outperform target-based schemes. Experimental studies which analyze differences between individual and team decisions are, e.g., BORNSTEIN and YANIV (1998), Bone, Hey, and SuCKLing (1999), VAN DiJK, SONNEMANS, and VAN Winden (2001), LAughlin, Bonner, and Miner (2002), Bornstein, Kugler, and Ziegelmeyer (2004), CADSBy, SONG, and TAPON (2004), Keser and Montmarquette (2004), Blinder and Morgan (2005), Cooper and Kagel (2005), Kocher and Sutter (2005), Kocher, Straub, and Sutter (2006), and Rockenbach, SadrieH, and MATAUSCHEK (in press). 
First, the principal offers a menu of two linear incentive contracts, one contract stipulating a fixed wage and a return share for IT and the other one stipulating a fixed wage and a return share for GT. Second, each agent decides for entering GT or IT and accepting the respective contract. Alternatively, an agent may reject both contracts and earn nothing. Third, each agent chooses an individual effort level. In IT this determines individual output and the according payoffs for the principal and the agent. In GT individual efforts of four group members determine group output and the according payoffs for the principal and each of the four agents. ${ }^{3}$

Since average individual productivity is higher in the group task than in the individual task, efficiency calls for group production. However, group production has the strategic structure of a public good game and will therefore induce free-riding, if agents decide rationally. Consequently, the principal cannot induce agents to select GT and to provide positive group effort by an appropriate pay contract; i.e., contract design is ineffective in stimulating group effort. Furthermore, economic rationality makes no differential prediction with respect to the agent's productivity. These rational predictions are contrasted by predictions that assume trust, reciprocity and cooperation among (at least) part of the agents. Accordingly, we predict a positive correlation between offered pay and the willingness to select GT as well as group effort. Furthermore, we predict that less productive agents choose GT less frequent than more productive agents.

We find support for the effectiveness of contract design in stimulating group performance. And, by employing different experimental treatments - symmetric worker productivities versus asymmetric productivities - we succeed in identifying the motivation effect and the selection effect of monetary incentives. To our knowledge this is one of the first experimental studies that systematically tackle these issues.

\footnotetext{
Note, that we do not allow for endogenous group formation in the sense of CORICELLI, FeHR, and FeLLNER (2004), Page, Putterman, and Unel (2004), Brosig, Margreiter, and WeimanN (2005), or AhN, IsAaC, and SALMON (in press)) where subjects can in some way influence with whom they want to be matched in a group task. There is also a recent study by VYRASTEKOVA, ONDERSTAL, and KONING (2006) with individual and team incentives in organizations. While it sounds as if it should be directly related to our study it is, in essence, not since there subjects after playing a trust game (to measure trust and reciprocity) could, given an exogenous contract, choose to work in a team or individually once for 10 periods and then were forced to work individually for the next 10 periods. Moreover, subjects could reward the other worker in a firm after efforts have been chosen.
} 


\section{The Model}

Consider a manager (principal) and a group of 16 workers (agent $j=1,2, \ldots, 16) .{ }^{4}$ Work can be organized either as individual task (IT) or as group task (GT). In IT each worker's effort results in an observable, individual return. In GT workers form groups of four, and the individual efforts of all four group members determine an observable group return. Workers may self-select into IT or GT, and individual returns as well as group returns are split between principal and respective agents according to an agreed-upon pay contract. This describes the basic ingredients of our principal-agent game.

Figure 1: Sequence of decisions in the base game

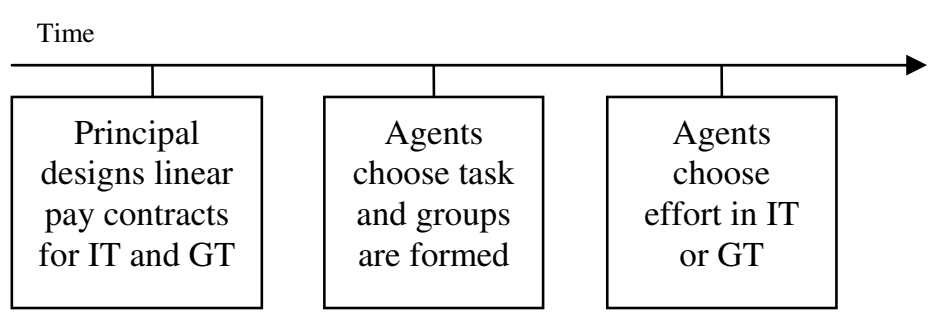

More formally, the game has ten periods and each period follows the rules of the base game which is depicted in Figure 1 and which will now be described in detail. It has three stages:

STAGE 1 (CONTRACT DESIGN): The principal offers two linear pay contracts, one for IT and one for GT. The pay contract for IT $w^{I T}=\left(f^{I T}, s^{I T}\right)$ comprises a fixed wage $f^{I T}$ and a return share $s^{I T}$ to be paid to the agent in case he/she chooses IT. The pay contract for GT $w^{G T}=\left(f^{G T}, s^{G T}\right)$ comprises a fixed wage $f^{G T}$ and a return share $s^{G T}$ to be paid to the agent in case he/she chooses GT. Fixed wages and return shares are restricted as follows:

$$
\begin{aligned}
& s^{I T}, s^{G T} \in\{0 \%, 10 \%, \ldots, 100 \%\} \\
& f^{I T}, f^{G T} \in\{-15,-14, \ldots,+15\}
\end{aligned}
$$

STAGE 2 (TASK SELECTION): Each agent can accept one of the two contracts $w^{I T}$ or $w^{G T}$ or reject both. If both are rejected, the agent does not work at all in the current period. If $w^{I T}$ is accepted this means that the agent works individually (IT) and will be paid according to $w^{I T}$. If $w^{G T}$ is accepted this means that the agent prefers to work in a group. This decision is preliminary since not all agents that are willing to work in a group can do so. Namely, they

4 For simplicity, we will explain the model and its theoretical solution for the numerical implementation of our experiment. Of course, it does hold more generally. 
are randomly matched in groups of four, and those who cannot be matched (at most three agents) have to decide again whether they accept contract $w^{I T}$ (and, consequently, work individually) or prefer not to work at all in the current period.

STAGE 3 (EFFORT CHOICES): Agents $j$ (with $j \in\{1,2, \ldots, 16\}$ ) who have accepted either IT or GT simultaneously choose individual work effort $e_{j} \in\{0,1, \ldots, 10\}$. Work effort is associated with cost (accruing to the agent) according to the cost function $c\left(e_{j}\right)=2 e_{j}$. Furthermore, in IT individual effort determines individual return $r_{j}^{I T}=3 e_{j}$. In GT the return of group $k$ is determined as follows: $r_{k}^{G T}=\sum_{l=1}^{4} q_{l} e_{l}$, i.e., it is the weighted sum of efforts of all four group members with the weight $q_{j}(j=1,2, \ldots, 16)$ being an individual productivity parameter.

In the experiment we applied two treatments, a symmetric treatment (SYM) in which $q_{j}=7.5$ was the same for all agents, and an asymmetric treatment (ASYM) in which productivity was $q_{j}=7.5$ (high productivity) for half of the agents while it was $q_{j}=2.5$ (low productivity) for the other half of the agents. It was publicly known whether the treatment was SYM or ASYM. In ASYM productivities were only privately known by each agent. Furthermore, players knew that half of the agents had high (low) productivity. Note that in addition to $q_{j}$ each agent has a productivity in IT - which is 3 for all agents. But, unless stated otherwise by "productivity" we refer to an agent's productivity in GT.

The choices as described above lead to the following base game payoffs: The agent's payoff in IT is

$$
\pi_{j}^{I T}=f^{I T}+s^{I T} \cdot r_{j}^{I T}-c\left(e_{j}\right)
$$

In GT (if agent $j$ is member of group $k$ ) the agent earns

$$
\pi_{j}^{G T}=f^{G T}+s^{G T} \cdot \frac{1}{4} r_{k}^{G T}-c\left(e_{j}\right)
$$

If neither IT nor GT was chosen, agent $j$ 's payoff is 0 .

Base game earnings of the principal are computed as follows: The principal has to pay fixed wages $f^{I T}$ (to all agents in IT) and $f^{G T}$ (to all agents in GT) and collects residual returns. Thus, the principal earns 


$$
\pi_{P}=\sum_{j \in I T}\left(\left(1-s^{I T}\right) \cdot r_{j}^{I T}-f^{I T}\right)+\sum_{k \in G T}\left(\left(1-s^{G T}\right) \cdot r_{k}^{G T}-4 f^{G T}\right)
$$

with $j \in \mathrm{IT}$ representing an agent who has chosen IT and with $k \in$ GT representing a group of four agents who have chosen GT.

This concludes the description of the base game. The entire game comprises ten repetitions of the base game (ten periods). The experimental participants knew they were playing a repeated game with a single principal facing 16 agents and that groups in GT were formed randomly (among those willing to work in groups). As explained above the game was either symmetric or asymmetric with respect to the productivity parameter $q_{j}$. In SYM the productivity was the same across agents for all ten periods. In ASYM each agent's productivity was fixed for all ten periods, but it was low (high) for half of the agents. Participants were informed about the distribution of productivity types and about their own type, but not about the types of other players.

\section{Theoretical Analysis and Behavioral Hypotheses}

We first describe the implications of efficiency and rationality, and then describe our main hypotheses.

\subsection{Efficiency}

In treatment SYM the sum of payoffs of the principal and all agents is maximized if all agents decide for GT and choose maximal effort. To see this note that marginal productivity is higher in GT than in IT, and that it is higher than marginal cost at all effort levels. The efficient sum of payoffs in the base game is 880 .

In treatment ASYM only agents with high group productivity $\left(q_{l}=7.5\right)$ should decide for GT and choose maximal effort. Agents with low group productivity $\left(q_{l}=2.5\right)$ should decide for IT and choose maximal effort, since in IT productivity is 3 and, thus, higher than in GT and higher than marginal cost. The efficient sum of payoffs in the base game is 520 .

\subsection{Rational Solution}

Let's consider behavior in period ten. If players are individually rational they will provide zero effort in GT ("free-riding"). Moreover, agents should not decide for GT in the first place. To see this, note that GT has the structure of a public good game and that freeriding is obviously the individually rational choice for all feasible pay contracts. 
Consequently the pay contract $w^{G T}$ offered by the principal may not feature a positive fixed wage $f^{G T}>0$, since otherwise the principal would incur a loss. In turn an agent may gain nothing by choosing GT and should strictly prefer IT if the pay contract $w^{I T}$ grants a positive (even if small) payoff. The principal can induce the agent to choose IT and provide maximal effort by offering $s^{I T}>2 / 3$ (incentive compatibility constraint) and a sufficiently large fixed wage $f^{I T}$ (participation constraint). This generates a surplus of 10 money units which can be appropriated by the principal. For example, the choices $s^{I T}=1, f^{I T}=-10$ and $e^{I T}=10$ are consistent with this equilibrium analysis. The sum of equilibrium payoffs in the base game is 160.

These arguments characterize rational play in period ten. By backward induction the same arguments hold for earlier periods. Overall, we conclude that all subgame perfect equilibria of the game induce the agent to select IT and choose maximal effort in the individual task, that $s^{I T}>2 / 3$ and that $f^{I T}$ is adjusted accordingly such that (almost) all surplus accrues to the principal. Furthermore, $f^{G T} \leq 0$, and $s^{G T}$ is unrestricted. If $s^{I T} \leq 2 / 3$ (off the equilibrium path), then effort in IT should be zero, and if the agent selects GT (off the equilibrium path), then effort in GT should be zero as well.

\subsection{Main Behavioral Hypotheses, Cooperation, Trust and Reciprocity}

The rational solution as worked out above provides (too) sharp predictions for subjects' decisions. One should not expect that equilibrium points are chosen exactly. Rather, we will focus on more robust predictions and comparative statics. Namely, note that the rational solution precludes that the principal may induce profitable work groups at all. He may induce agents to select GT only by designing a non-profitable contract, and even in that case the agents will not provide effort. Thus, we consider the following hypotheses:

Hypothesis 1: Contract design has no impact on the agent's willingness to select GT.

Hypothesis 2: If subjects have selected GT, contract design has no impact on effort in GT.

The rational solution also makes no differential prediction with respect to the agent's group productivity.

Hypothesis 3: More productive group workers select GT equally likely as less productive group workers. 
Hypothesis 4: More productive group workers will provide the same (zero) effort as less productive group workers.

These basic implications of the rational choice model were the point of departure for our study. We will contrast them by behavioral hypotheses that are based on considerations of trust, reciprocity and cooperation - which may be summarized as the social-emotional model of behavior. Explicit examples of such models are provided by, e.g., FEHR and SCHMIDT (1999), BOLTON and OCKENFEls (2000), DufwENBERG and KirCHSTEIGER (2004), and FALK and FISCHBACHER (2006). If one assumes that the population of players consists of different types ("egoistically motivated" types versus "socially motivated" types), it is possible to consistently explain trust and reciprocal or cooperative behavior (see, e.g., FEHR and SCHMIDT (2000) for details). Besides theoretical modeling it has also been shown in simple principal-agent experiments (see, e.g., GÜTH, KlOSE, KÖNIGSTEIN, and SCHWALBACH (1998), ANDERHUB, GÄCHTER, and KÖNIGSTEIN (2002), FEHR and GÄCHTER (2002), GÄCHTER, KESSLER, and KÖNIGSTEIN (2006)) that more generous contract offers by the principal may induce higher effort levels. We refer to this as the "trust and reciprocity" mechanism. ${ }^{5}$ Furthermore, basic public good experiments (see, e.g., FALKINGER, FEHR, GÄCHTER, and WINTER-EBMER (2000), GÄCHTER and FEHR (2000) and for comprehensive surveys of early literature LEDYARD (1995) and DAVIS and HOLT (1993)) have shown that subjects may cooperate to some extent in such environments. Extrapolating these findings to our more complex setting we predict:

\section{Hypothesis 5: More generous GT-contracts induce more agents to select GT.}

This prediction runs counter to Hypothesis 1. It also implies that some - if not many agents will select GT at all.

\section{Hypothesis 6: Effort in GT and offered payment are positively correlated.}

This is contrary to Hypothesis 2 and implies that subjects will, indeed, provide positive effort in GT. If Hypotheses 5 and 6 hold, one might further on consider the influence of the agent's group productivity. ${ }^{6}$ If the agent has a concern for other agents and/or the principal, there is no reason for low productivity types to join a group since this is inefficient and reduces the other players' payoffs. Therefore, in contrast to Hypothesis 3 we predict:

For an extensive survey on fairness and reciprocity in different contracting situations see FEHR and GÄCHTER (2000), and GÄCHTER and FEHR (2002).

6 Studies which, in quite a different context, address the issue of heterogeneous workforce are, e.g., PRAT (2002) and MEIDINGER, RULLIÈRE, and VILLEVAL (2003). 
Hypothesis 7: Agents with low group productivity will select GT less frequently than agents with high group productivity.

Nonetheless, we expect at least some low productivity agents to select GT. Reasons might be either "noisy play" or - assuming a two type population of egoistic and socially motivated players - that egoistic types expect higher gains in GT than IT (and, consequently, select GT despite the low productivity). Egoistic types with low productivity should provide zero effort. Socially motivated types with low productivity - given they have selected GT in the first place - should provide positive effort. Actually, they should provide the same effort as socially motivated types with high productivity. Since we do not know whether a player is egoistic or socially motivated on average we expect:

Hypothesis 8: Agents with low group productivity provide less effort in GT than agents with high group productivity.

Note that hypotheses 1 to 4 are Null-Hypotheses for the Alternative Hypotheses 5 to 8 , respectively. Thus, we have actually only a small set of predictions to be tested below. Furthermore, all of the hypotheses concern the selection of GT and effort in GT rather than behavior in IT. This should not be surprising since self-selection into groups, effort in groups and the interaction of both with contract design are the main and most innovative issues of our study. Nevertheless, in addition we will analyze behavior in IT to some extent, e.g., to check whether our data are in line with other studies on incentives for individual effort provision.

\section{Experimental Procedures}

The experiment was conducted in the experimental economics lab at the University of Erfurt. In total 323 students of various disciplines participated in the experiment. They were recruited via the internet from a large data base with GREINER's ORSEE (2004). The experiment was computerized, using the experimental software z-Tree by FISCHBACHER (in press). Each subject participated only in one session. Each session comprised two parts with each part featuring the ten-period principal-agent game as described above. The second part was announced not before completion of the first part. In some sessions subjects played the symmetric game (treatment SYM) first and the asymmetric game (treatment ASYM) second. In other sessions the sequence was reversed. The second part data were collected for exploratory purposes (within-subject effects). In order not to complicate the statistical analysis the second part data will not be analyzed in this paper. 
In the laboratory the participants were visually separated by booths. They received written instructions ${ }^{7}$ and had to answer control questions to ensure their understanding of the game rules and the calculation of payoffs. Experimental decisions were communicated via the network. The participants were randomly and anonymously assigned to one of three roles: one principal, eight agents with low group productivity and eight agents with high group productivity (in treatment ASYM). Roles were labeled "participant A", "B" and "C" respectively. They stayed anonymous and constant throughout the entire experiment and subjects knew this. In treatment SYM we applied the same labeling although group productivity was the same for "participant B" and "participant C". Some details of the experimental procedures are listed in Table 1.

Table 1: Design of the experiment

\begin{tabular}{lcc}
\hline \hline & \multicolumn{2}{c}{ treatment ordering } \\
& ASYM-SYM & SYM-ASYM \\
\cline { 2 - 3 } \# of rounds & $2 \times 10$ & $2 \times 10$ \\
treatment played in first 10 rounds & ASYM & SYM \\
treatment played in second 10 rounds & SYM & ASYM \\
\# of participants & 153 & 170 \\
thereof \# agents & 144 & 160 \\
thereof \# principals & 9 & 10 \\
\# of sessions & 9 & 10 \\
group size in GT & 4 & 4 \\
\hline \hline
\end{tabular}

In each period after the decisions had been made, the computer program calculated the resulting period payoffs. IT-agents (agents who had selected IT) were informed about their own payoff. GT-agents (agents who had selected GT) were informed about their own group return and their individual payoff. The principal was informed about the number of agents who had chosen IT and GT and about all individual and group returns. Payoffs were denoted in points and were later on exchanged into cash at the rates of 1 Euro per 100 points for the principal and 1 Euro per 10 points for agents. This was known to all participants. Different exchange rates for principal and agents were applied in order to avoid extremely large earnings by the principal. For each part of the experiment the participants received a fixed

\footnotetext{
Original instructions were written in German. They are available upon request from the authors. A
} translation is provided in Appendix A. 
payment of 50 points. Sessions took about 2 hours and average earnings were about $22.00 €$ for principals and $20.20 €$ for agents. ${ }^{8}$

After completion of the decision part of the experiment subjects answered a small questionnaire (i.a., age, gender, field of study, decision process) and were paid anonymously.

\section{Empirical Results}

\subsection{Descriptive Statistics}

Altogether we ran 10 sessions with treatment ordering SYM-ASYM and 9 sessions with reversed ordering ASYM-SYM - i.e., a session featured 2 x 10 periods. As noted above we only analyze the data from the first 10 periods in order not to complicate the analysis by including within-subject influences of SYM versus ASYM. Thus, we analyze 190 contract design choices (19 principals by 10 periods) and 3040 decisions (304 agents by 10 periods) upon task selection and effort. In this subsection we present distributions and some descriptive statistics of the data and discuss informally how they are related to our hypotheses. More formal statistical models and parameter test will be provided later on.

Table 2: Frequencies for agents' selection of task

\begin{tabular}{c|ccc}
\hline \hline task & $G T$ & $I T$ & NONE \\
\hline frequency & $59.61 \%$ & $27.17 \%$ & $13.22 \%$ \\
\hline \hline
\end{tabular}

Table 2 shows frequencies for the agents' selection of task. Figure 2 displays histograms for contracts offered by principals, and Figure 3 displays histograms for agents' effort choices. Counter to the rational solution GT is chosen in many cases (59.61\%, see Table 2), and effort in GT is not zero but positive in most cases (see Figure 3). In IT we observe many intermediate effort levels. This is inconsistent with rationality but may be explained by trust and reciprocity. Namely, intermediate contract offers might trigger intermediate effort responses.

We do observe return shares above $2 / 3$ in IT, but shares below $2 / 3$ are also frequent. Overall, we find substantial dispersion in contract design, task selection and effort, which in the following will be analyzed in more detail.

\footnotetext{
8 The net student wage rate was about $7 €$ per hour at the time of the experiment. In the first (second) part of the experiment 1 (7) out of 304 agents ended up with a total loss of $0.80 €(1.70 €)$. We did not collect these losses.
} 
Figure 2: Histograms for contracts offered by principal
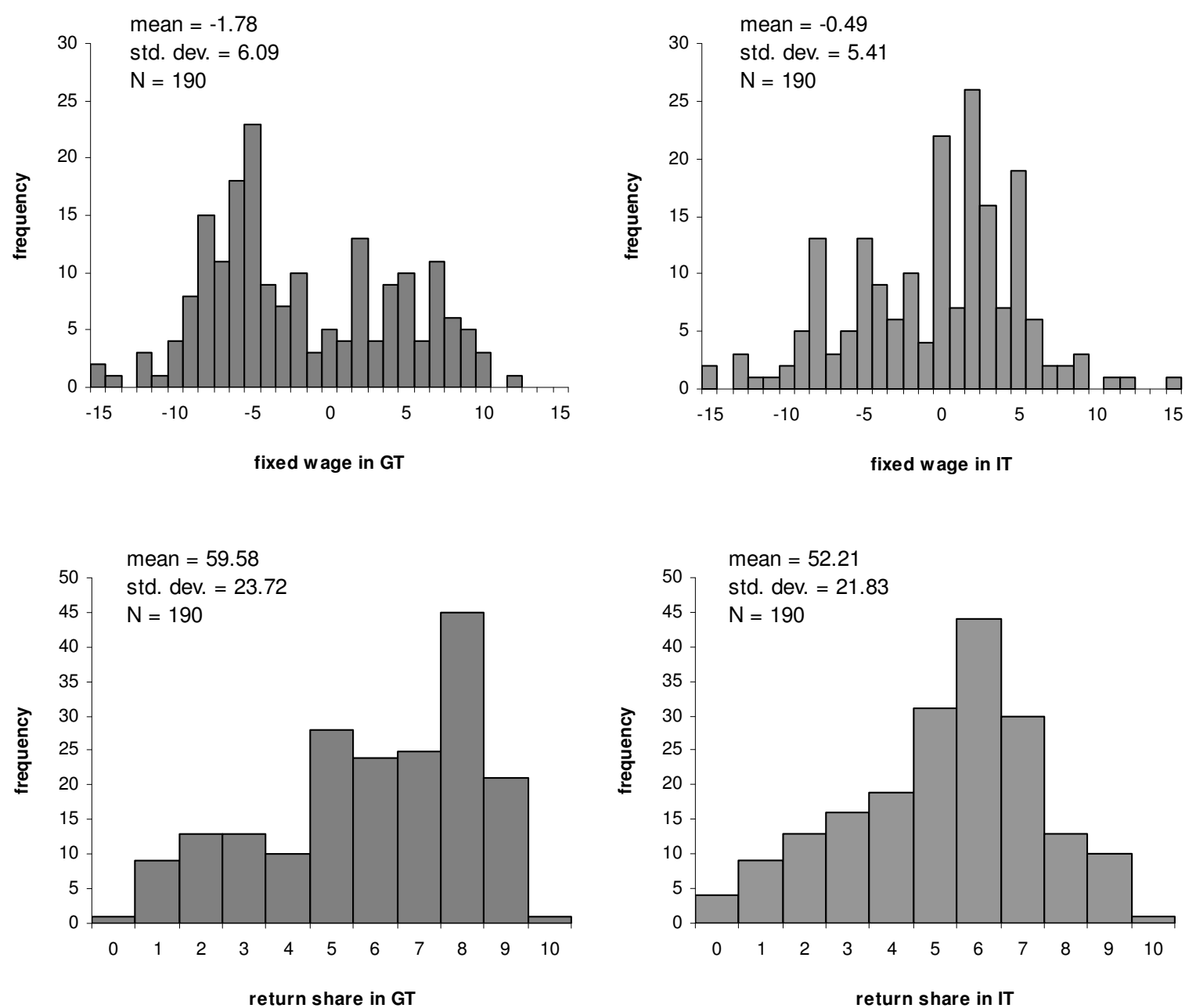

Figure 3: Histograms for agents' effort choices
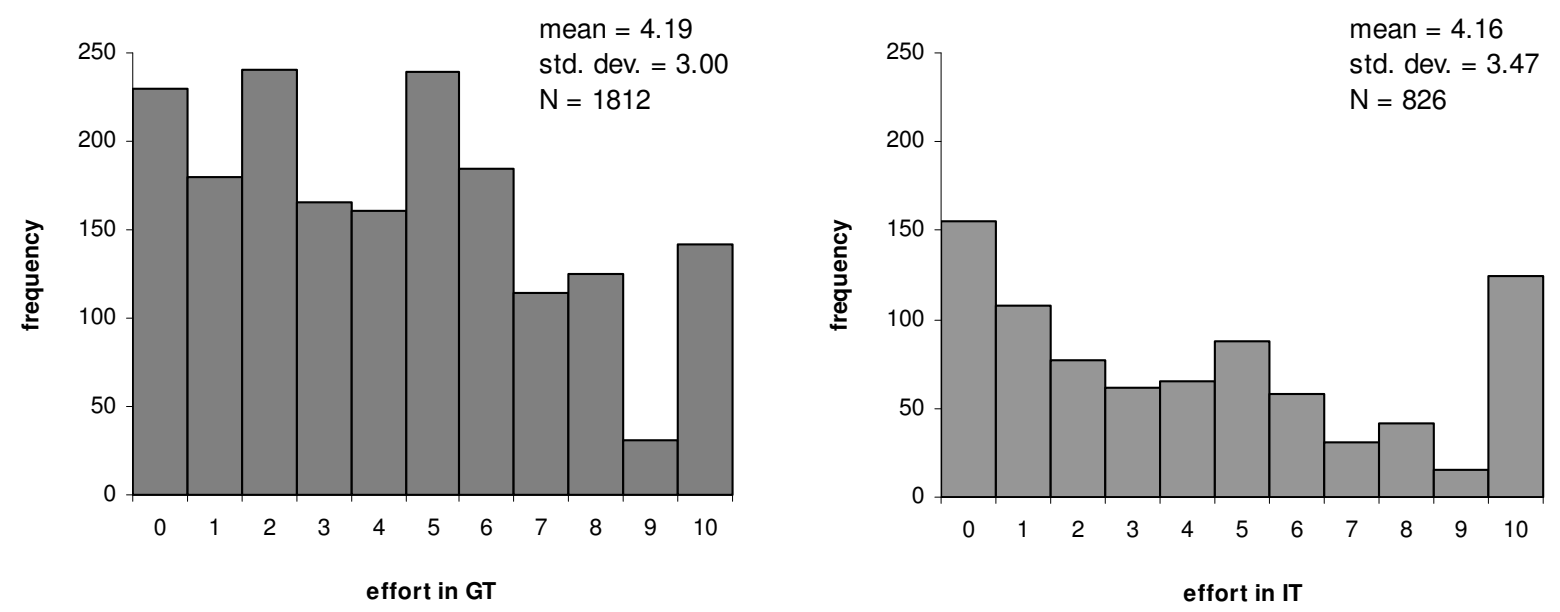


\subsection{Regression Models}

We analyze the agents' choice of task (GT, IT or NONE) by a multinomial regression and their effort choices in the chosen task $\left(e_{j}^{G T}\right.$, and respectively $\left.e_{j}^{I T}\right)$ by two tobit regressions. In running the latter two regressions we have to consider sample selection bias since selection into GT and IT is not random. To account for this we follow the two-step Heckman procedure. ${ }^{9}$

Table 3: Regression results on agents' task selection

\begin{tabular}{|c|c|c|c|}
\hline \multicolumn{4}{|c|}{$\begin{array}{l}\text { dependent variable: task selection } \\
\text { method: maximum-likelihood multinomial logistic regression } \\
\text { comparison group: individual task }\end{array}$} \\
\hline variable & coefficient & std. error & $\begin{array}{c}p \text {-value } \\
\text { (one-tailed) }\end{array}$ \\
\hline \multicolumn{4}{|c|}{ probability of selecting GT versus IT } \\
\hline return share in IT & -0.0309 & 0.0051 & 0.000 \\
\hline fixed wage in IT & -0.1744 & 0.0216 & 0.000 \\
\hline return share in $G T$ & 0.0489 & 0.0067 & 0.000 \\
\hline fixed wage in $G T$ & 0.1882 & 0.0189 & 0.000 \\
\hline dummy Low Productivity & -0.1602 & 0.1233 & 0.194 \\
\hline dummy SYM & 0.6488 & 0.2057 & 0.002 \\
\hline period & 0.1938 & 0.0841 & 0.021 \\
\hline period $^{2}$ & -0.0062 & 0.0076 & 0.421 \\
\hline constant & -1.2306 & 0.5081 & 0.015 \\
\hline \multicolumn{4}{|c|}{ probability of selecting NONE versus IT } \\
\hline return share in IT & -0.0248 & 0.0074 & 0.001 \\
\hline fixed wage in IT & -0.2506 & 0.0361 & 0.000 \\
\hline return share in $G T$ & 0.0101 & 0.0053 & 0.057 \\
\hline fixed wage in $G T$ & 0.0036 & 0.0165 & 0.829 \\
\hline dummy Low Productivity & -0.0997 & 0.0727 & 0.170 \\
\hline dummy SYM & -0.0224 & 0.3755 & 0.952 \\
\hline period & 0.2951 & 0.1181 & 0.012 \\
\hline period $^{2}$ & -0.0123 & 0.0147 & 0.239 \\
\hline constant & -1.4612 & 0.5722 & 0.011 \\
\hline $\begin{array}{l}\text { number of } \\
\text { matching groups } \\
\text { observations }\end{array}$ & \multicolumn{3}{|c|}{$\begin{array}{l}19 \\
3040\end{array}$} \\
\hline
\end{tabular}

Table 3 presents the results for the agents' choice of task, and Tables 4 and 5 report estimation results for effort choices. The upper panel in Table 3 displays influences upon the probability of choosing GT versus IT (the reference category). Accordingly the probability of choosing GT rather than IT significantly decreases in $s^{I T}$ and $f^{I T}$, and significantly increases in $s^{G T}$ and $f^{G T}$. This strongly rejects Hypothesis 1 ("no influence of contract design on 
selection of GT") in favor of the alternative, Hypothesis 5 ("generous contracts induce more frequent selection of GT"). The coefficient for dummy SYM is positive and the one for dummy Low Productivity is negative, though not significant. Thus, the willingness to select GT rather than IT is significantly lower in treatment $A S Y M$ than $S Y M$ and it is even lower for low productivity agents than for high productivity agents. The latter finding rejects Hypothesis 3 ("no difference") in favor of Hypothesis 7 ("low productivity agents select GT less frequently than high productivity agents"). Variables period and period ${ }^{2}$ were included to control for the influence of time. Accordingly, the frequency of selecting GT increases over time.

The lower panel of Table 3 shows influences upon the probability of choosing NONE versus IT. This probability decreases significantly - and quite plausibly - in $s^{I T}$ and $f^{I T}$. Other effects are insignificant except for period and $s^{G T}$. The latter is difficult to interpret

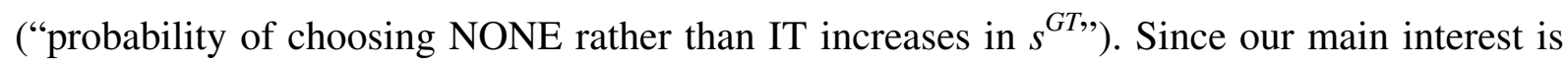
the choice of GT versus IT and not the choice of NONE versus IT, we will not discuss this part of the regression analysis any further.

Table 4: Regression results on effort in GT

\begin{tabular}{lccc}
\hline \hline $\begin{array}{l}\text { dependent variable: } \text { effort in group task } \\
\text { method: tobit regression with clustering } \text { on matching groups }\end{array}$ \\
\hline variable & coefficient & std. error & $\begin{array}{c}\text { p-value } \\
\text { (one-tailed) }\end{array}$ \\
\hline return share in GT & 0.0605 & 0.0126 & 0.000 \\
fixed wage in GT & 0.0551 & 0.0580 & 0.342 \\
dummy Low Productivity & -1.7089 & 0.2083 & 0.000 \\
dummy SYM & -0.5533 & 0.4130 & 0.180 \\
period & -0.2737 & 0.1392 & 0.049 \\
period2 & 0.0054 & 0.0093 & 0.564 \\
Mill's ratio & 0.1418 & 0.8182 & 0.862 \\
constant & 2.3560 & 1.2945 & 0.069 \\
\hline number of & & prob $>\chi^{2}$ & 0.0000 \\
matching groups & 19 & & \\
observations & 1812 & & \\
\hline \hline
\end{tabular}

Table 4 displays the result of a tobit regression with effort in GT $\left(e_{j}^{G T}\right)$ as dependent variable. In line with Hypothesis 6 and rejecting Hypothesis 2 there is a positive correlation between offered payment and effort in GT due to the positive and significant influence of $s^{G T}$. The effect of fixed wage $\left(f^{G T}\right)$ is positive as well but insignificant.

\footnotetext{
9 We include the inverse Mill's ratio as regressor in the analysis of efforts.
} 
Furthermore, low productivity agents provide significantly less group effort than high productivity agents (dummy Low Productivity). This supports Hypothesis 8 against Hypothesis 4. Variables period, period ${ }^{2}$ and Mill's Ratio were included to control for time and sample selection bias (analogously in the regression reported in Table 5).

Table 5: Regression results on effort in IT

\begin{tabular}{lccc}
\hline \hline $\begin{array}{l}\text { dependent variable: } \text { effort in individual task } \\
\text { method: tobit regression with clustering on matching groups }\end{array}$ \\
\hline variable & coefficient & std. error & $\begin{array}{c}\text { p-value } \\
\text { (one-tailed) }\end{array}$ \\
\hline return share in IT & 0.1011 & 0.0162 & 0.000 \\
fixed wage in IT & -0.0047 & 0.0624 & 0.940 \\
dummy Low Productivity & -0.1897 & 0.4049 & 0.639 \\
period & -0.6494 & 0.2991 & 0.030 \\
period2 & 0.0510 & 0.0269 & 0.058 \\
Mill's ratio & -0.1546 & 0.7536 & 0.837 \\
constant & 0.4562 & 1.8769 & 0.808 \\
\hline number of & & prob $>\chi^{2}$ & 0.0000 \\
matching groups & 19 & & \\
observations & 826 & & \\
\hline \hline
\end{tabular}

Table 5 reports a similar regression, but now with effort in IT $\left(e_{j}^{I T}\right)$ as dependent variable. The effect of $s^{I T}$ is significantly positive, while the effect of $f^{I T}$ is insignificant. Thus, higher offered payment induces higher effort in IT. This is in line with other studies on principal-agent experiments with individual tasks (e.g., ANDERHUB, GÄCHTER, and KÖNIGSTEIN (2002) and GÄCHTER, KESSLER, and KÖNIGSTEIN (2006)).

\section{Digression: A Formal Model of Social Preferences}

In this section we apply the model of FEHR and SCHMIDT (FS-model) to show formally that selecting GT and high group effort is consistent with a specific model of social preferences. Suppose that players exhibit social preferences represented by the following utility function:

$$
U_{j}=\pi_{j}-\alpha_{j} \cdot \frac{1}{n-1} \cdot \sum_{i \neq j}^{n} \max \left\{\pi_{i}-\pi_{j}, 0\right\}-\beta_{j} \cdot \frac{1}{n-1} \cdot \sum_{i \neq j}^{n} \max \left\{\pi_{j}-\pi_{i}, 0\right\}
$$

where $\pi_{j}$ and $\pi_{i}$ represent monetary payoffs of players $j$ and $i$. Fehr and Schmidt refer to this as a model of inequity aversion since payoff differences of player $j$ compared to player $i$ ceteris paribus reduce player $j$ 's utility. The model contains standard preferences - i.e., sole concern for money (egoistic preferences) - as boundary case $\left(\alpha_{j}=\beta_{j}=0\right)$. The parameter $\alpha_{j}$ 
$\left(\beta_{j}\right)$ represents the degree of aversion against unfavorable (favorable) inequity. For reasons of plausibility (see FEHR and SCHMIDT (1999) for a discussion) we impose the following restrictions:

$$
\beta_{j} \leq \alpha_{j} \text { and } 0 \leq \beta_{j}<1
$$

The parameter $n$ represents the number of players which player $j$ compares with, i.e., it represents the size of the social reference group. We will apply the FS-model to show the following:

1. Depending on preferences the selection of GT and high group effort may be rational in groups of highly productive agents.

2. This may be rational for groups of mixed productivity as well, but less attractive for low productivity agents than for high productivity agents.

3. Selection of GT and high group effort by inequity averse agents may be rational even if the population also contains egoistic agents.

In order to keep the analysis simple we assume that preferences and productivities are common knowledge, that agents compare their payoff within the work group but not with agents outside the work group and not with the principal, and, finally, that the principal only cares for monetary payoff. Given these assumptions we determine a subgame perfect equilibrium (SPE) of the game for different compositions of the group of agents.

Proposition 1: If $q_{j}=\frac{15}{2}$ and agents are sufficiently inequity averse - within the range defined in (5) - there exists a SPE with $e_{j}^{*}=10$ for all $j=1,2,3,4$.

The proofs of all propositions are provided in Appendix B. The SPE requires $\beta_{j} \geq \frac{1}{16}$ for all $j=1,2,3,4$.

Proposition 2: If a group consists of two high productive agents $q_{j}=\frac{15}{2}$ and two low productive agents $q_{j}=\frac{5}{2}$, there exists a SPE with $e_{j}^{*}=10$ for all $j=1,2,3,4$ if agents are sufficiently inequity averse. 
Here, the proposed solution requires $\beta_{j} \geq \frac{11}{16}$ for low productivity agents and $\beta_{j} \geq \frac{1}{16}$ for high productivity agents.

Proposition 3: Consider a group of agents where three agents $(j=1,2,3)$ are inequity averse and one agent $(j=4)$ is egoistic - i.e., $\alpha_{4}=\beta_{4}=0$. Furthermore, let $q_{j}=\frac{15}{2}$ for $j=$

$1,2,3$. There exists a SPE where all agents select GT and with effort choices $e_{4}^{*}=0$, $e_{j}^{*}=10$ for $j=1,2,3$ if inequity aversion is sufficiently high.

The solution requires $\beta_{j} \geq \frac{3}{32}+\frac{1}{2} \alpha_{j}$ for $j=1,2,3$, and together with (5) this implies that $\alpha_{j}$ and $\beta_{j}$ are at least $\frac{3}{16}$.

Propositions 1 to 3 indicate that selection of GT and high group effort are consistent with the assumption of rational, but inequity averse, players. This supports the basic finding of our experiment that there is selection of GT and positive group effort. It is important in our view that the theoretical result holds not only in uniform populations of highly productive and inequity averse agents, but also in mixed populations with low productivity agents or egoistic agents. Proposition 2 indicates furthermore that selecting GT and high group effort should be observed less likely for low productive agents since it requires a higher degree of inequity aversion than for highly productive agents.

These results were derived under restrictive assumptions to illustrate in a simple theoretical framework that a model of social preferences may rationalize our experimental findings. If one assumes that player types (productivity and/or preferences) are private information, and that the proportion of types is commonly known, it is more difficult to provide a rigorous solution. However, from propositions 1 to 3 we can conclude (without proof) that selection of GT and high group effort is rational even with private information if the proportion of low productive and/or egoistic agents is sufficiently low.

\section{Selection Effect versus Motivation Effect of Group Incentives}

Our experiment gives rise to what LAZEAR (2000) refers to as selection effect versus motivation effect in personnel economics. He provides an empirical example where the introduction of a new payment scheme by a firm induced an increase in average work effort due to two kinds of effects: a selection effect - i.e., low productive workers leaving the firm and high productive workers entering the firm - and a motivation effect - i.e., more effort by 
those workers who stayed in the firm. ${ }^{10}$ While LAZEAR studied the influence of changing the pay scheme for an individual task, we might transfer his basic question to study selection versus motivation within our framework as well. Namely, if the principal offers a more favorable contract to a mixed population of socially motivated agents, one can conceive changes in the firm's earnings due to the following three different effects:

- Size Effect: It may induce more agents to choose GT, which increases earnings if average (per agent) earnings from GT are higher than earnings from IT.

- Selection Effect: It may increase the proportion of highly productive and socially motivated agents in GT compared to low productive or egoistic agents. This effect will, ceteris paribus, increase average earnings in GT.

- Motivation Effect: It may induce those agents which choose GT anyway to provide higher effort. This obviously increases average effort.

We determine these effects by calculating predicted values for task selection and effort choice from the regression models we presented above assuming mean values for all variables except $s^{G T}$. For $s^{G T}$ we set either 0.50 (scenario 1) or 0.80 (scenario 2) which are the 0.25 percentile value, and respectively, the 0.75 -percentile value.

Table 6 reports that the predicted number of agents in GT is 8.03 in scenario 1 and 12.74 in scenario 2 (size effect). Furthermore, it reports that mean effort in GT increases from 3.38 (scenario 1) to 5.20 (scenario 2). Since this increase of 1.82 units is due to both, the motivation effect and the selection effect, we run additional analyses to separate motivation from selection. So, first, we estimated tobit regressions (dependent variable: $e^{G T}$; independent variables: $s^{G T}$ and $f^{G T}$ ) for each individual subject, and, second, determined the effort difference between scenario 2 and scenario 1 for each individual. This measure represents the motivation effect, and its median value is 0.55 . Accordingly, about $30 \%(0.55 / 1.82)$ of the increase in effort from scenario 1 to scenario 2 is due to the motivation effect, and about $70 \%$ (the residual) is due to the selection effect. Thus, while monetary incentives induce both a motivation effect and a selection effect, the latter is larger in size than the former.

10 LAZEAR (2000) studies performance pay and productivity at Safelite Glass, the largest automobile windshield company in the United States, which switched from hourly wages to piece-rate pay based on the number of windshields installed. Overall, the company's productivity increased by $44 \%$ - however, only half of the increase could be attributed to the motivation effect. The rest was due to the new scheme's effect on the composition of the workforce. 
An interesting further question is whether and to what extent the selection effect works via productivity or preference type. I.e., the selection effect can mean a change with respect to the productivity of agents (productivity-based selection effect) and/or with respect to preference types, if one considers a population of heterogeneous agents à la FEHR/SCHMIDT (preference-based selection effect). Using the regression results we determine predicted proportions of high and, respectively, low productivity agents in GT. Table 6 reports almost identical proportions of each type of agent in both scenarios. Accordingly, average productivity in GT is largely unaffected by the assumed change in the pay contract; the productivity-based selection effect is negligible. In turn this implies that the selection effect in our experiment solely means selection by preference type.

All three effects, size effect, motivation effect and selection effect, can be compared by looking at the predicted sum of efforts in GT (see Table 6). It increases from 27.14 (scenario 1) to 66.25 (scenario 2). About $18 \%$ of the increase is due to the motivation effect and $41 \%$ each is due to the selection effect and the size effect.

Table 6: Predicted values for two scenarios

\begin{tabular}{lcc}
\hline \hline & scenario 1 & scenario 2 \\
\hline predicted number of agents in GT & 8.03 & 12.74 \\
predicted effort in GT & 3.38 & 5.20 \\
predicted sum of efforts in GT & 27.14 & 66.25 \\
predicted proportion of high productivity agents in GT & $51.59 \%$ & $50.66 \%$ \\
predicted proportion of low productivity agents in GT & $48.41 \%$ & $49.34 \%$ \\
\hline \hline
\end{tabular}

\section{Concluding Remarks}

The standard model of economic rationality precludes group effort, if the group task is structured as a public good game. Moreover, since this is independent of the specification of a linear pay contract, the principal may not use contract design (within the class of contracts considered here) to induce more selection of the group task and higher group effort. This prediction, the point prediction as well as the comparative statics, is challenged by considerations of trust, reciprocity and cooperation which have been observed in several other experimental studies on games simpler than ours. Public good experiments have documented that agents do cooperate. Principal agent experiments have shown that a trustful principal who offers a generous pay contract which is unconditional on effort might nevertheless induce a 
reciprocal, high effort choice. Extrapolating these findings suggests that the principal can indeed influence task selection and group effort. This is supported by our data. Offering a higher return share $s^{G T}$ induces more agents to select GT and higher group effort. Increasing fixed wage has a positive effect on the selection of GT as well and a positive but insignificant effect on group effort. Since fixed wage and return share are highly correlated ${ }^{11}$, partial effects should be taken with care. But, the joint effect clearly documents that more generous pay contracts indeed increase both participation in group tasks and group effort.

Furthermore, task selection and effort are influenced by individual productivities and players knowledge about asymmetry or symmetry. Agents are more inclined to choose the group task if productivities are equal. If productivities are asymmetric and agents have selected GT in the first place, more productive agents provide higher group effort.

The total effect of contract design on group effort - i.e., the increase in the sum of efforts in GT due to higher payment - can be decomposed into size effect (41\%), motivation effect $(18 \%)$ and selection effect (41\%). Assuming agents with social preferences the results suggest that selection works via preference type rather than productivity type. Better payment increases the share of socially motivated agents in groups relative to the share of egoistic agents in groups.

Overall the experiment has shown that contract design can play a major role in getting agents to self-select into work groups. Careful design of a linear contract can strongly increase the number of group participants (size effect) and overall efficiency. To our knowledge, combining linear contract design with endogenous choices of individual versus group tasks has not been studied experimentally before.

\footnotetext{
${ }^{11}$ The Spearman rank correlation coefficient is -0.57 and highly significant $(\mathrm{p}<0.001, \mathrm{~N}=190)$.
} 


\section{References}

ANDERHUB, Vital; GäCHTER, Simon and KÖNIGSTEIN, Manfred (2002): Contracting and Fair Play in a Simple Principal-Agent Experiment, Experimental Economics 5, 5-27.

Ahn, Toh-Kyeong; IsAaC, Mark R. and SALMON, Timothy C. (in press): Endogenous Group Formation, Journal of Public Economic Theory.

Blinder, Alan S. and Morgan, John (2005): Are Two Heads Better Than One? Monetary Policy by Committee, Journal of Money, Credit, and Banking 37(5), 798-812.

Bone, John D.; HeY, John D. and SuckLIng, John R. (1999): Are Groups More (or Less) Consistent Than Individuals?, Journal of Risk and Uncertainty 18(1), 63-81.

Bolton, Gary and OCKEnfels, Axel (2000): ERC: A Theory of Equity, Reciprocity and Competition, American Economic Review 90, 166-193.

BoRnSTEIN, Gary and YANIV, Ilan (1998): Individual and Group Behavior in the Ultimatum Game: Are Groups More "Rational" Players?, Experimental Economics 1, 101-108.

BornsteIn, Gary; Kugler, Tamar and ZIEGELMEYER, Anthony (2004): Individual and Group Behavior in the Centipede Game: Are Groups More "Rational" Players?, Journal of Experimental Social Psychology 40, 599-605.

Brosig, Jeannette; MARgreiter, Magdalena and WeIMANn, Joachim (2004): Endogenous Group Formation and the Provision of Public Goods: The Role of Promises and Lies, Working paper, University of Cologne, University of Innsbruck and University of Magdeburg.

CADsby, Bram C.; Song, Fei and TAPON, Francis (2004): The Effects of Compensation Schemes on Self-Selection and Work Productivity: An Experimental Investigation, mimeo, University of Guelph and York University.

CHE, Yeon-Koo and Yoo, Seung-Weon (2001): Optimal Incentives for Firms, American Economic Review 91, 525-541.

Cooper, David J. and Kagel, John H. (2005): Are Two Heads Better Than One? Team versus Individual Play in Signaling Games, American Economic Review 95(3), 477-509.

Coricelli, Giorgio; FeHr, Dietmar and Gerlinde, Fellner (2004): Partner Selection in Public Good Experiments, Journal of Conflict Resolution 48(3), 356-378.

VAN DiJK, Frans; Sonnemans, Joep and VAN Winden, Frans (2001): Incentive Systems in a Real Effort Experiment, European Economic Review 45, 187-214.

DAvis, Douglas D. and HolT, Charles A. (1993): Experimental Economics, Princeton University Press, Princeton.

DufwenberG, Martin and KIRCHSTEIGER, Georg (2004): A Theory of Sequential Reciprocity, Games and Economic Behavior 47, 268-298.

FALK, Armin and FISCHBACHER, Urs (2006): A Theory of Reciprocity, Games and Economic Behavior 54(2), 293-315.

FALKINGER, Josef; FeHR, Ernst; GÄCHTER, Simon and WinTER-EbMER, Rudolf (2000): A Simple Mechanism for the Efficient Provision of Public Goods: Experimental Evidence, American Economic Review 90(1), 247-264. 
FEHR, Ernst and GÄCHTER, Simon (2000): Cooperation and Punishment in Public Goods Experiments, American Economic Review 90(4), 980-994.

FEHR, Ernst and GÄCHTER, Simon (2000): Fairness and Retaliation: The Economics of Reciprocity, Journal of Economic Perspectives 14, 159-181.

FEHR, Ernst and GäCHTER, Simon (2002): Do Incentives Contracts Undermine Voluntary Cooperation?, Working Paper No. 34, Institute for Empirical Research in Economics, University of Zurich.

FEHR, Ernst and SchmidT, Klaus M. (1999): A Theory of Fairness, Competition, and Cooperation, Quarterly Journal of Economics 114, 817-868.

FEHR, Ernst and SCHMIDT, Klaus M. (2000): Fairness, Incentives and Contractual Choices, European Economic Review 44(2), 393-421.

FISCHBACHER, URS (in press): z-Tree: Zurich Toolbox for Ready-made Economic Experiments, Experimental Economics.

GÄCHTER, Simon and FEHR, Ernst (2002): Fairness in the Labour Market - A Survey of Experimental Results, in: BoLLE, Friedel and LEHMANN-WAFFENSCHMIDT, Marco (ed.): Surveys in Experimental Economics: Bargaining, Cooperation and Election Stock Markets, Physica, Heidelberg, 95-132.

GÄCHTER, Simon; KeSSLER, Esther and KöNIGSTEIN, Manfred (2006): Performance Incentives and the Dynamics of Voluntary Cooperation, Working paper, University of Nottingham and University of Erfurt.

GreINER, Ben (2004): The Online Recruitment System ORSEE 2.0 - A Guide for the Organization of Experiments in Economics, Working Paper Series in Economics 10, University of Cologne.

GÜTH, Werner; KLOSE, Wolfgang; KöNIGSTEIN, Manfred and SchWALBACH, Joachim (1998): An Experimental Study of a Dynamic Principal-Agent Relationship, Managerial and Decision Economics 19, 327-341.

HANSEN, Daniel G. (1997): Worker Performance and Group Incentives, Industrial and Labor Relations Review 51(1), 37-49.

HAMILTON, Barton H.; NicKERSON, Jack A. and OwAN, Hideo (2003): Team Incentives and Worker Heterogeneity: An Empirical Analysis of the Impact of Teams on Productivity and Participation, Journal of Political Economy 111(3), 465-497.

Jehn, Karen A.; NorthCRAfT, Gregory B. and Neale, Margaret A. (1999): Why Differences Make a Difference: A Field Study of Diversity, Conflict, and Performance of Workgroups, Administrative Science Quarterly 44, 741-763.

Keser, Claudia and Montmarquette, Claude (2004): Voluntary Teaming and Effort, CIRANO Working Paper No. 49, Montréal.

Kocher, Martin G.; Strauß, Sabine and SutTer, Matthias (2006): Individual or Team Decision-Making - Causes and Consequences of Self-Selection, Games and Economic Behavior 56, 259-270.

Kocher, Martin G. and SutTer, Matthias (2005): The Decision Maker Matters: Individual versus Group Behaviour in Experimental Beauty-Contest Games, Economic Journal $115,200-223$. 
Laughlin, Patrick R.; Bonner, Bryan L. and Miner, Andrew G. (2002): Groups Perform Better Than the Best Individuals on Letter-to-Numbers Problems, Organizational Behavior and Human Decision Processes 88(2), 605-620.

LAZEAR, Edward P. (2000): Performance Pay and Productivity, American Economic Review 90(5), 1346-1361.

LEDYARD, John O. (1995): Public Goods: A Survey of Experimental Research, in: KAGEL, John H. and Roth, Alvin E. (ed.): Handbook of Experimental Economics, Princeton University Press, Princeton, 111-194.

Meidinger, Claude; Rullière, Jean-Louis and Villeval, Marie-Claire (2003): Does TeamBased Compensation Give Rise to Problems When Agents Vary in Their Ability?, Experimental Economics 6, 253-272.

NAlbantian, Haig R. and Schotter, Andrew (1997): Productivity Under Group Incentives: An Experimental Study, American Economic Review 87(3), 314-341.

Page, Talbot; Putterman, Louis and Unel, Bulent (2005): Voluntary Association in Public Goods Experiments: Reciprocity, Mimicry and Efficiency, Economic Journal 115, 1032-1053.

PrAT, Andrea (2002): Should a Team be Homogenous?, European Economic Review 46, 1187-1207.

PREndergast, Canice (1999): The Provision of Incentives in Firms, Journal of Economic Literature 37(1), 7-63.

Rockenbach, Bettina; SAdRIEH, Abdolkarim and MATAuscheK, Barbara (in press): Teams Take the Better Risks, Journal of Behavior and Organization.

Vyrastekova, Jana; Onderstal, Sander and Koning, Pierre (2006): Team Incentives in Public Organizations, CPB Discussion Paper No. 60, Netherlands Bureau for Economic Policy Analysis.

WEISS, Andrew (1987): Incentives and Worker Behavior: Some Evidence, in: NALBANTIAN, Haig R. (ed.): Incentives, Cooperation, and Risk Sharing, Rowman \& Littlefield, Totowa, N.J., 137-150. 


\section{Appendix A - Instructions}

Instructions for the treatment ordering ASYM-SYM

(Original instructions were in German. They are available from the authors upon request. Both the principal and the agent received the same instructions.)

You are participating in two decision experiments. At the end you will be paid according to your performance. Therefore it is important, that you fully understand the following instructions.

\section{$\underline{\text { Instructions to experiment } 1}$}

\section{- Roll Assignment}

17 participants are taking part in the decision experiment 1 . Each participant has one of three roles. One participant is of the type A (participant A), eight participants are of the type B (participant B) and eight participants are of the type C (participant C). Your type is randomly determined at the beginning of the experiment and is displayed to you on your screen. Your type remains constant throughout the experiment and is shown for reminding purposes on the top of the screen.

\section{- Payoff}

The experiment consists of several rounds. During the experiment payoffs are given in points and displayed on your account. At the beginning each participant's account amounts to 50 points. Profits are added to your account, losses are subtracted. Also in the case of a negative account balance you continue to participate in the experiment. Due to profits you can again obtain a positive account balance. At the end your payoffs are converted into Euro and paid to you in cash. If at the end your account balance is negative, you receive a payoff of 0 Euro for experiment 1 . Following rules apply to the conversion of points into Euros:
- For participant $\mathrm{B}$ and $\mathrm{C}$ :
10 points $=1$ Euro
- For participant A:
100 points $=1$ Euro

\section{- Other details}

Please note that during the experiment communication is not allowed. If you have a question, please raise your hand out of the cubicle. All decisions are made anonymously. No other participant will learn your name and your monetary payoff.

Good luck!

\section{$\underline{\text { Experiment 1 }}$}

Experiment 1 consists of 10 rounds and 17 participants: one participant A, eight participants $\mathrm{B}$ and eight participants $\mathrm{C}$. 


\title{
Procedure of each period:
}

1. Participant A proposes a remuneration scheme for an individual project (project I) and a remuneration scheme for a group project (project II) which are disclosed to all participants B and C. Remuneration scheme I determines the payoff for project I and consists of a return share I (percentage of the individual return) and a fixed wage I. Remuneration scheme II determines the payoff for project II and consists of a return share II (percentage of the group return) and a fixed wage II.

2. Each participant B (C) decides whether she accepts the remuneration scheme I, the remuneration scheme II or neither of them.

\section{3.a. Project $I$ is chosen}

Given a participant B (C) has accepted the remuneration scheme I, she participates in project I (individual project) and chooses an investment level $(0,1, \ldots$, or 10$)$ with the corresponding investment costs (investment costs $=2 \mathrm{x}$ investment level). The chosen investment level determines an individual return (individual return $=3 \mathrm{x}$ investment level).

Following payoffs result:

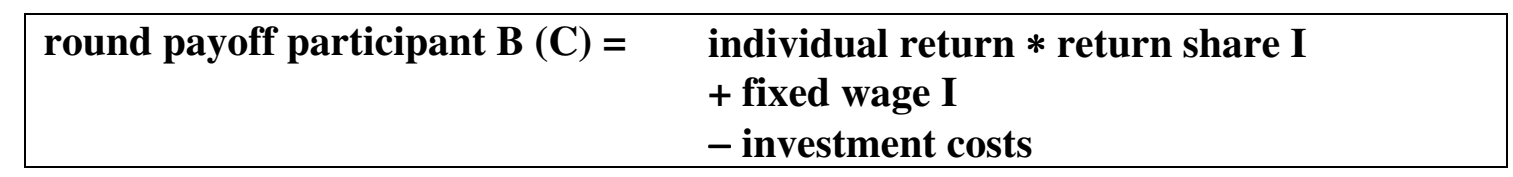

round payoff participant $A=$

\author{
individual return $*(\mathbf{1 0 0 \%}$ - return share $I)$ \\ - fixed wage I
}

This means: Participant B $(\mathrm{C})$ receives the agreed return share I of the individual return plus the fixed wage I minus the own investment costs. Participant A receives the remaining return share of the individual return minus the fixed wage I. Further, as the case may be participant A receives payoffs from other individual projects or group projects.

Displayed information to the participants: Participant B (C) gets to know her individual return and her own round payoff. Participant $A$ is informed about the number of participants in individual projects. Additionally, she only gets to know the sum of all individual returns and the sum of her payoffs from individual projects.

\section{3.b. Project II is chosen}

Given several participants $\mathrm{B}$ or $\mathrm{C}$ have accepted the remuneration scheme II, groups of 4 members are formed out of these participants who want to participate in project II (group project). Group members can be of different types. The group composition is random. Redundant participants cannot participate in a group project. They are informed and can decide, whether to alternatively accept remuneration scheme I or not. If so, see point 3.a. If not, see point 3.c.

Each of the four members of a group chooses an investment level $(0,1, \ldots$, or 10) with the corresponding investment costs (investment costs $=2 \mathrm{x}$ investment level) without the knowledge of the other group members' decisions or types. The chosen individual investment level determines the individual return contribution of each group member. 
Individual return contribution of participant $\mathrm{B}=2.5 \mathrm{x}$ investment level Individual return contribution of participant $\mathrm{C}=7.5 \mathrm{x}$ investment level

The sum of the four individual return contributions is the group return.

Following payoffs result:

\begin{tabular}{|ll|}
\hline round payoff participant $B(C)=$ & $\begin{array}{l}\text { group return } *(\text { return share } \text { II }) / 4 \\
+ \text { fixed wage } \text { II } \\
\text { - investment costs }\end{array}$ \\
\hline round payoff participant $A=$ & $\begin{array}{l}\text { group return } *(100 \% \text { - return share } \text { II }) \\
-4 * \text { fixed wage II }\end{array}$ \\
\hline
\end{tabular}

This means: Each group member receives a forth of the agreed share of the group return (return share II) plus the fixed wage II minus the own investment costs. Participant A receives the remaining share of the group return minus the four fixed wages. Further, as the case may be participant A receives payoffs from other individual projects or group projects.

Displayed information to the participants: Participant B (C) only gets to know the group return and her own round payoff. Participant $\mathrm{A}$ is informed about the number of participants in group projects. Additionally, she only gets to know the sum of all group returns and the sum of her payoffs from group projects.

\section{3.c. No project is chosen}

Given a participant B $(C)$ has neither accepted remuneration scheme I nor remuneration scheme II, she participates in no investment project in this round and receives the payoff 0 . Participant A receives as the case may be only payoffs from other individual projects or group projects.

\section{Rules for the remuneration scheme:}

- The return share can equal $0 \%, 10 \%, \ldots$, or $100 \%$. Return shares I and II can be different.

$\circ$ The fixed wage can equal $-15,-14, \ldots, 0,1, \ldots$ or 15 . Fixed wages I and II can also be different.

Within the given limits return share and fixed wage can freely be combined. A positive fixed wage means a payment of participant $A$ to the respective participant $B(C)$. A negative fixed wage means a payment of a participant B (C) to participant A.

\section{End of a period and further rounds}

After the investment decisions or as the case may be the rejection of the proposed remuneration schemes payoffs are calculated. The round ends. Your round payoff and your account balance are displayed to you. The next round starts according to the same rules. 


\section{Experiment 2}

Experiment 2 consists of 10 rounds and 17 participants: one participant A, eight participants B and eight participants C. All participants are of the same type as in experiment 1. Besides the calculation of the individual return contributions in project II (see below) the rules are the same as in experiment 1. At the beginning of experiment 2 each participant's account amounts to 50 points. Your payoff in experiment 1 remains unaffected by your payoff in experiment 2 .

The individual return contributions in project II are the following:

- Individual return contribution of participant $\mathrm{B}=7.5 \mathrm{x}$ investment level

- Individual return contribution of participant $C=7.5 \mathrm{x}$ investment level 


\section{Appendix B - Proof of Propositions}

Proposition 1: If $q_{j}=\frac{15}{2}$ and agents are sufficiently inequity averse - within the range defined in (5) - there exists a subgame perfect equilibrium with $e_{j}^{*}=10$ for all $j=1,2,3,4$.

\section{Proof:}

1. Suppose $s^{G T}=1$ and that agents have selected GT. We will first determine the conditions for equilibrium in this subgame and solve the overall game thereafter. Without loss of generality let's consider the decision of agent 1 . Given the proposed equilibrium effort profile all agents earn the same (i.e., there is no inequity) and utility $U_{1}^{*}$ is:

$$
U_{1}^{*}=\pi_{1}^{*}=f^{G T}+\frac{1}{4} \sum_{1}^{4} \frac{15}{2} \cdot 10-20=f^{G T}+55
$$

Next we determine the deviation utility. Since utility (4) is linear in effort we need to consider only a deviation $e_{1}^{*}=0$. In this case the players' payoffs are:

$$
\begin{aligned}
& \pi_{1}=f^{G T}+\frac{1}{4} \cdot 0+\frac{1}{4} \cdot \sum_{2}^{4} \frac{15}{2} \cdot 10=f^{G T}+\frac{225}{4} \\
& \pi_{i}=f^{G T}+\frac{225}{4}-20=f^{G T}+\frac{145}{4} \quad, \forall i=2,3,4
\end{aligned}
$$

Thus, player 1 earns more than players 2, 3 and 4 and incurs favorable inequity. Her utility is:

$$
U_{1}=f^{G T}+\frac{225}{4}-\beta_{1} \frac{1}{3} \sum_{2}^{4} 20=f^{G T}+\frac{225}{4}-20 \beta_{1}
$$

For equilibrium we need $U_{1}^{*} \geq U_{1} \Leftrightarrow U_{1}^{*}-U_{1} \geq 0$ which is equivalent to $\beta_{1} \geq \frac{1}{16}$.

Consequently, $e_{j}^{*}=10$ for all $j=1,2,3,4$ is an equilibrium in the subgame if $\beta_{j} \geq \frac{1}{16}$ for all $j=1,2,3,4$.

2. Now we consider the overall game. If the principal can induce the agents to select GT and choose maximal effort, the group surplus (group return minus sum of cost of all group members) is $300-80=220$, which may be appropriated by the principal by suitable choices of $f^{G T}$ and $s^{G T}$, e.g. $f^{G T}=-55$ and $s^{G T}=1$. If instead the principal induces selection of IT and maximal effort in IT, each agent generates a surplus of 10. Consequently the principal 
prefers to induce selection of GT, and she can do so by making the IT-contract sufficiently unattractive. q.e.d.

Note that the above arguments characterize the path of a subgame perfect equilibrium (SPE). Rational behavior in other subgames may be determined similarly, but is not of interest for our purposes. The principal may not earn a higher SPE-payoff. On the contrary, the agents just get their outside option payoff; i.e., they are indifferent between selecting GT or no contract at all. But, by offering a marginally higher $f^{G T}$ the principal can induce the agents to strictly prefer GT. Finally, by similar reasoning one can show that contracts with $s^{G T}$ $<1$ and appropriate $f^{G T}$ maximal effort are feasible in SPE as well. However, this imposes stronger restrictions on inequity aversion (larger values of parameter $\beta_{j}$ ).

Proposition 2: If a group consists of two high productive agents $q_{j}=\frac{15}{2}$ and two low productive agents $q_{j}=\frac{5}{2}$, there exists a subgame perfect equilibrium with $e_{j}^{*}=10$ for all $j=1,2,3,4$ if agents are sufficiently inequity averse.

\section{Proof:}

1. Again, we will first determine the conditions for equilibrium in the subgame where agents have selected GT and given $s^{G T}=1$, and solve the overall game thereafter. Without loss of generality let $q_{1}=q_{2}=\frac{5}{2}$ and $q_{3}=q_{4}=\frac{15}{2}$. Given the proposed effort profile all agents earn the same and utilities:

$$
U_{j}^{*}=\pi_{j}^{*}=f^{G T}+\frac{1}{4}\left(2 \cdot \frac{5}{2} \cdot 10+2 \cdot \frac{15}{2} \cdot 10\right)-20=f^{G T}+30 \text { for all } j=1,2,3,4 .
$$

If player 1 deviates by $e_{1}^{*}=0$ payoffs and utility are:

$$
\begin{aligned}
& \pi_{1}=f^{G T}+\frac{175}{4} \\
& \pi_{i}=f^{G T}+\frac{95}{4}, \forall i=2,3,4 \text { and } \\
& U_{1}=f^{G T}+\frac{175}{4}-20 \beta_{1}
\end{aligned}
$$

Again, since utility is linear in effort we consider only a deviation $e_{1}^{*}=0$. For equilibrium we need $U_{1}^{*} \geq U_{1} \Leftrightarrow U_{1}^{*}-U_{1} \geq 0$ which is equivalent to $\beta_{1} \geq \frac{11}{16}$. Applying similar reasoning one can derive the equilibrium condition $\beta_{3} \geq \frac{1}{16}$ for player 3 and therefore $e_{j}^{*}=10$ 
for all $j=1,2,3,4$ is an equilibrium in the subgame if $\beta_{j} \geq \frac{11}{16}$ for low productivity agents and if $\beta_{j} \geq \frac{1}{16}$ for high productivity agents.

2. Now we consider the overall game. According to the proposed equilibrium the group surplus, which may be appropriated by the principal, is $200-80=120$, and it is larger than the surplus sum that may be generated in IT $(4 \cdot 10=40)$. Thus, the principal will induce these equilibrium choices by $f^{G T}=-30$ and $s^{G T}=1$ and by making the IT-contract sufficiently unattractive. q.e.d.

Regarding unreached subgames and other equilibria a similar reasoning as for proposition 1 applies.

Proposition 3: Consider a group of agents where three agents $(j=1,2,3)$ are inequity averse and one agent $(j=4)$ is egoistic - i.e., $\alpha_{4}=\beta_{4}=0$. Furthermore, let $q_{j}=\frac{15}{2}$ for $j=1$, 2, 3. There exists a subgame perfect equilibrium where all agents select GT and with effort choices $e_{4}^{*}=0, e_{j}^{*}=10$ for $j=1,2,3$ if inequity aversion is sufficiently high.

\section{Proof:}

1. Suppose $s^{G T}=1$ and agents have selected GT. In this subgame the payoffs and utilities according to the proposed equilibrium effort profile are:

$$
\begin{aligned}
& \pi_{j}^{*}=f^{G T}+\frac{145}{4} \text { for all } j=1,2,3 \\
& U_{4}^{*}=\pi_{4}^{*}=f^{G T}+\frac{225}{4} \\
& U_{j}^{*}=f^{G T}+\frac{145}{4}-\frac{20}{3} \alpha_{j} \text { for all } j=1,2,3
\end{aligned}
$$

Thus, agents 1, 2 and 3 suffer from unfavorable inequity. If player 1 deviates by $e_{1}^{*}=0-$ since utility is linear in effort do not have to consider other deviations - payoffs and utility are:

$$
\begin{aligned}
& \pi_{1}=\pi_{4}=f^{G T}+\frac{150}{4} \\
& \pi_{2}=\pi_{3}=f^{G T}+\frac{70}{4} \\
& U_{1}=f^{G T}+\frac{150}{4}-\frac{40}{3} \beta_{1}
\end{aligned}
$$


Equilibrium requires $U_{1}^{*} \geq U_{1} \Leftrightarrow U_{1}^{*}-U_{1} \geq 0$ which is equivalent to $\beta_{1} \geq \frac{3}{32}+\frac{1}{2} \alpha_{1}$. Accordingly, and since $e_{4}^{*}=0$ is obviously rational for agent 4 the proposed solution holds in this subgame if

$$
\beta_{j} \geq \frac{3}{32}+\frac{1}{2} \alpha_{j} \text { for } j=1,2,3 .
$$

It can easily be verified that this inequality and the restrictions in (5) can be satisfied simultaneously by subsets of the $\left(\alpha_{j}, \beta_{j}\right)$-parameter space that have positive measure in the unit square.

2. The principal wants to induce the proposed choices if the resulting payoff is larger than the feasible payoff of 40 in IT. Furthermore, the contract choice $f^{G T}, s^{G T}$ has to satisfy the participation constraint $U_{j}^{*} \geq 0$ for all $j=1,2,3,4$. The latter holds if participation is granted for the agent which is most inequity averse among the agents. Suppose the highest value of inequity aversion is $\alpha_{j}=1$. Consequently, for $s^{G T}=1$ and $f^{G T}=-\frac{355}{12}$ participation is granted. The principal earns $\frac{355}{3}$ which is larger than the feasible payoff in IT. q.e.d.

Regarding unreached subgames and other equilibria a similar reasoning as for proposition 1 applies. 